\title{
POTENCIAL DE FOSFITOS NA INDUÇÃO DA RESISTÊNCIA EM PLANTAS DE SOJA
}

\author{
Janaína Bruzamarello ${ }^{1}$, Vinicius Tadeu Franceschi ${ }^{2}$, Nean Locatelli Dalacosta ${ }^{2}$, Iandra
} Gonçalves $^{1}$, Sérgio Miguel Mazaro ${ }^{3}$, Emerson Reis ${ }^{4}$

\footnotetext{
${ }^{1}$ Engenheiro(a) Agrônomo(a), Universidade Tecnológica Federal do Paraná (UTFPR), Dois Vizinhos, PR. Email: janaina.bruzamarello@ hotmail.com, iandragon93@hotmail.com.

${ }^{2}$ Mestrando, Pós Graduação em Agroecossitemas, Universidade Tecnológica Federal do Paraná (UTFPR), Dois Vizinhos, PR. E-mail: viniciusfranceschi@outlook.com, neanlocatelli@gmail.com.

${ }^{3}$ Engenheiro Agrônomo, Prof. Dr., Universidade Tecnológica Federal do Paraná, Dois Vizinhos, PR. E-mail sergio@utfpr.edu.br.

${ }^{4}$ Engenheiro Agrônomo, Spraytec Fertilizantes, Maringá, PR. E-mail: emerson.reis@spraytec.com.
}

\section{Recebido: 20/02/2017; Aceito: 29/08/2018}

RESUMO: O presente trabalho teve como objetivo avaliar o potencial de produtos à base de fosfitos de potássio, cobre e manganês, na ativação da Resistência Sistêmica Adquirida (RSA) em plantas de soja. O delineamento foi inteiramente casualizado, com 5 tratamentos constituídos de fosfito de potássio $0,002 \%$, fosfito de manganês $0,002 \%$, fosfito de cobre 0,002\%, Acibenzolar-S-Metil $(0,005 \%)$ e a testemunha (água destilada), em quatro repetições. O experimento foi realizado na Universidade Tecnológica Federal do Paraná (UTFPR), Campus Dois Vizinhos, em casa de vegetação. A cultivar de soja foi a Nidera 5909, semeada em vasos com capacidade de 10 litros, e as plantas conduzidas até o estádio fenológico R1 (Início do florescimento) momento onde ocorreu os tratamentos. Antes da aplicação dos tratamentos (tempo inicial) e após a aplicação dos tratamentos, em intervalos de 24, 48, 96 e 192 horas, foram realizadas coletas de materiais vegetais para as análises bioquímicas, onde quantificou-se a atividade de enzimas relacionadas à ativação da RSA, sendo a fenilalanina amônia-liase, quitinase e $\beta-1,3$ glucanase. A inoculação dos esporos da ferrugem asiática foi realizada em 48 horas após a aplicação dos tratamentos. Os resultados demonstraram que os fosfitos a base de potássio, cobre, manganês e o ASM, possuem capacidade de ativar enzimas relacionadas à patogenicidade, demonstrando a ativação da Resistência Sistêmica Adquirida em plantas de soja. Tais ativações apresentam especificidade de ação, bem como atuam em mecanismos distintos de defesa.

Palavras-chave: Glycine max. Resistência sistêmica adquirida. Controle alternativo.

\section{PHOSPHITES POTENTIAL FOR INDUCTION OF RESISTANCE IN SOYBEAN PLANTS}

ABSTRACT: This present study had as objective to evaluate the potential of products based on potassium phosphite, copper and manganese, the activation of the Systemic Acquired Resistance (SAR) in soybean plants. The used design was completely randomized 
with 5 treatments was composed of potassium phosphite $0.002 \%$, manganese phosphite $0.002 \%$, copper phosphite $0.002 \%$, acibenzolar-S-methyl $(0.005 \%)$ and untreated plants (distilled water), with four replications. The experiment was conducted at the Federal Technological University of Paraná (UTFPR), located in Dois Vizinhos - PR, in the greenhouse. The soybean cultivar used was Nidera 5909, 10 liter capacity, and plants led to the growth stage R1 (Beginning of flowering) moment occurred treatments. Before application of treatments (starting time) and after the application of treatments at intervals of 24, 48, 96 and 192 hours, samples was taken of plant material for biochemical analysis, which quantified the activity of enzymes related to activation SAR, being phenylalanine ammonia-lyase, chitinase and $\beta-1,3$ glucanase. Inoculation of the asiatic rust spores was carried out in 48 hours after treatment application. The results demonstrated that the potassium phosphite, copper, manganese and ASM, has ability to activate enzymes related to pathogenicity, demonstrating the activation of Systemic Acquired Resistance in soybean plants. Such activations present specificity of action.

Key words: Glycine max. Systemic acquired resistance. Alternative control.

\section{INTRODUÇÃO}

Com o aumento crescente de área e volume de produção, a soja (Glycine max) se encontra atualmente como a principal cultura em âmbito nacional (COMPANHIA NACIONAL DE ABASTECIMENTO - CONAB, 2017). A produtividade é afetada por inúmeros fatores, sendo as doenças, responsáveis pela redução de 15 a 20\%, podendo chegar a $100 \%$ de perdas. Dentre elas, a ferrugem asiática (Phakopsora pachyrhizi) é a principal doença da soja, responsável pela desfolha precoce, que implicam na formação, enchimento de vagens e peso final do grão (EMPRESA BRASILEIRA DE PESQUISA AGROPECUÁRIA - EMBRAPA, 2013; EMBRAPA, 2017).

Com o uso intensivo de fungicidas no controle de doenças, selecionou populações resistentes de fitopatógenos no campo (XAVIER et al., 2013; SCHMITZ et al., 2013). Fungicidas inibidores de succinato da desmetilação (ISDH) perdeu a eficiência para o controle da ferrugem-asiática da soja, em um estudo realizado na safra 2016/2017, variando entre $17 \%$ a $21 \%$ de controle. Os demais grupos de fungicidas apresentaram baixa porcentagem de controle, resultados esses semelhantes a safra anterior 2015/2016 (EMBRAPA, 2017).

Assim, diversos trabalhos vêm sendo desenvolvidos, associando aos fungicidas, indutores de resistência como o Acibenzolar-S-Metil (DEBONA et al., 2009; CARVALHO et al., 2013). Ou ainda, produtos como os fosfitos, na busca de melhorar a eficiência dos fungicidas no controle de doenças, seja pela ação direta ou de indução de resistência (CARMONA e SAUTUA, 2011; NEVES e BLUM, 2014;).

As plantas possuem o poder de reagir às agressões das doenças, mediante as respostas de defesa, as quais são ativados pela interação de uma molécula elicitora ou indutora, e as 
proteínas da membrana da célula vegetal. Essas respostas estão associadas a reações bioquímicas e fisiológicas, as quais promovem a defesa vegetal, sendo denominada de indução de resistência (DIAS e RANGEL, 2007).

Dentre as enzimas que atuam na ativação, estão a fenilalanina amônia-liase, a qual atua na rota dos fenilpropanóides na síntese de compostos fenólicos, como as fitoalexinas, e a síntese de lignina. Ainda, a $\beta-1,3$ glucanase e a quitinase, enzimas hidroliticas que atuam na degradação da parede celular do patógeno, dificultando ou impedindo sua ação patogênica, bem como estão diretamente relacionadas à ativação da RSA (DURRAN e DONG, 2004; LABANCA, 2002).

Em um estudo realizado por Melo et al. (2017) com fosfito de potássio em cotilédones de soja e mesocótilops de sorgo, mostrou-se eficiente na indução do acúmulo de fitoalexinas, onde o aumento da dose do produto proporcionou um aumento progressivo de fitoalexinas em ambas as culturas. Assim como para Costa et al. (2017), onde verificou que o uso de fosfito de potássio no controle de antracnose em feijão, incrementou a atividade de diversas enzimas, dentre elas a quitinase, $\beta-1,3$ glucanase e peroxidase, responsáveis por induzir respostas de defesa vegetal.

O presente trabalho teve como objetivo avaliar o potencial dos fosfitos a base de potássio, cobre, manganês, e o ASM, no comportamento das enzimas relacionadas à patogenicidade, e com isso o processo de ativação da Resistência Sistêmica Adquirida em plantas de soja.

\section{MATERIAL E MÉTODOS}

O experimento foi conduzido em casa de vegetação, na Universidade Tecnológica Federal do Paraná - UTFPR, Campus Dois Vizinhos, localizada na região Sudoeste do Paraná, a qual se encontra a 509 metros de altitude, pertencendo ao $3^{\circ}$ Planalto Paranaense com clima Cfa (Subtropical úmido mesotérmico), segundo a classificação Köppen-Geiger (KOTTEK et al., 2006). As análises bioquímicas foram feitas no Laboratório de Fitopatologia da Universidade.

A cultivar de soja utilizada foi a NIDERA 5909, com peso de mil grãos totalizando 179 gramas. A escolha baseou-se na cultivar mais utilizada na região. A soja foi semeada em vasos de 10 litros contendo solo classificado em Latossolo Vermelho Distroférico (EMBRAPA, 2013), os quais foram acondicionados em bancadas na casa de vegetação automatizada, dispondo de irrigação por gotejamento do tipo espaguete. A taxa de semeadura foi de 10 sementes por vaso, com posterior raleio em estádio V5, passando para 06 plantas por vaso. As sementes não tiveram nenhum tratamento químico, para não haver efeito dos produtos na ativação de resistência das plantas.

O delineamento foi inteiramente casualizado, com 5 tratamentos constituídos de fosfito de potássio 0,002\% (Ultra K®), fosfito de manganês 0,002\% (Ultra Mn®), fosfito de cobre $0,002 \%$ (Cubo®), Acibenzolar-S-Metil (0,005\%) e a testemunha (água destilada), em 
quatro repetições. A aplicação foi via micro-aspersão na parte aérea da planta, sendo 2mL.planta ${ }^{-1}$, considerando uma na dose de 150 L.ha $^{-1}$.

A aplicação dos tratamentos ocorreu no estádio fenológico R1 (Início do florescimento), sendo que anterior a aplicação (Inicial) e em intervalos de 24, 48, 96 e 192 horas, após a aplicação, foram realizadas coletas de material vegetal para análises bioquímicas, a fim de verificar a atividade enzimática em tempos distintos ao longo do ciclo da cultura. A coleta foi realizada de folhas sadias e não injuriadas no terço médio da planta, coletando 2 folhas por planta, sendo essas com o peso em torno de 0,1 grama, as quais foram acondicionadas em papel alumínio e armazenadas em freezer, para posterior análises bioquímicas. Ainda, ocorreu a inoculação dos esporos da ferrugem asiática, 48 horas após a aplicação dos tratamentos.

A coleta do patógeno para posterior inoculação, foi proveniente de folhas infectadas presentes em lavouras do campus, em um estádio de desenvolvimento avançado, onde retirou-se folhas com sintomas visuais e alocou-se em caixas de gerbox contendo papel filtro umedecido com água destilada, para o estabelecimento de câmera úmida, mantido a $26^{\circ} \mathrm{C}$ em BOD com fotoperíodo de 12 horas, havendo ambiente favorável para a esporulação. Preparou-se a solução de esporos, de P. pachyrhizi na concentração de $0,9 \mathrm{x}$ 105 uredinosporos/ml, dispersos em água destilada com Tween $(0,5 \%)$ e aplicado em todos os tratamentos.

As amostras de tecido foliar coletadas na casa de vegetação, foram maceradas em almofariz com $5 \mathrm{~mL}$ de solução tampão borato de sódio $0,1 \mathrm{M}(\mathrm{pH} 8,8)$, juntamente com 0,3 $\mathrm{g}$ de micropérolas de vidro, 0,2 $\mathrm{g}$ de resina Dowex 1-X8 e 0,3 g de Polivinilpolipirolidona (PVPP). Posteriormente, o material foi centrifugado $\left(20.000 \mathrm{~g} / 30 \mathrm{~min}\right.$ a $\left.4^{\circ} \mathrm{C}\right)$ e o sobrenadante coletado, para quantificação das proteínas totais, fenilalanina amônia-liase, quitinase e $\beta$-1,3-glucanase.

Nas análises bioquímicas, a determinação da atividade da fenilalanina amônia-liase (FAL) foi de acordo com a metodologia descrita por Kuhn (2007), por meio da quantificação colorimétrica do ácido trans-ciânico liberado do substrato fenilalanina. Utilizou-se 0,25g da amostra juntamente com 3,0mL do tampão TRIS - $\mathrm{HCl}$ pH 8,0 acondicionados em tubos ependorfe e centrifugado por $10 \mathrm{~min}$ a $4^{\circ} \mathrm{C}$ a $6000 \mathrm{rpm}$, subsequente uma alíquota de $200 \mu \mathrm{L}$ foi repassada por tubo de ensaio, com mais $3,0 \mathrm{~mL}$ do tampão de extração, onde a solução foi agitada em vortéx, obtendo-se assim, o extrato enzimático. Deste extrato, transferiu-se $1,5 \mathrm{~mL}$ para outro tubo de ensaio, com mais $1,0 \mathrm{~mL}$ do tampão de extração e $0,5 \mathrm{~mL}$ de fenilalanina. Agitou-se novamente em vórtex para homogeneização. Logo após, os tubos foram incubados em banho-maria por $45 \mathrm{~min}$ a $40^{\circ} \mathrm{C}$, ao retirar, colocou-se em banho-maria de gelo por 5 min para interromper a reação e assim realizar a leitura em espectrofotômetro a 290nm.

Para quantificação das proteínas totais, após a maceração das amostras de tecido foliar em almofariz com $5 \mathrm{~mL}$ de solução tampão fosfato $0,2 \mathrm{M}(\mathrm{pH} 7,5)$, o material foi centrifugado $\left(14.000 \mathrm{~g} / 10 \mathrm{~min}\right.$ a $\left.4^{\circ} \mathrm{C}\right)$ e o sobrenadante coletado. Utilizou-se o teste de 
BRADFORD (1976) para quantificação do conteúdo total de proteínas nas amostras. A leitura foi realizada em espectofotômetro, a $595 \mathrm{~nm}$, com soro albumina bovina como padrão.

Para dosagem das atividades de quitinase, seguiu-se os procedimentos descritos por Wirth e Wolf (1992), com adequações, utilizando $200 \mu \mathrm{L}$ de "CM-chitin-RBV" (2,0 mg mL-1), $200 \mu \mathrm{L}$ do sobrenadante e $600 \mu \mathrm{L}$ de tampão acetato. Posteriormente, incubado por 20 minutos em uma temperatura de $40^{\circ} \mathrm{C}$, onde em seguida paralisou-se a reação com a adição de $200 \mu \mathrm{L}$ da solução de $\mathrm{HCl}$ 1,0 M. Avaliou-se a atividade através da liberação de oligômeros solúveis de "chitin-azure", a partir de quitina carboximetilada marcada com remazol brilhante violeta 5R -RBV (Sigma Aldrich®), oriunda da quitina carboximetilada marcada pelo remazol brilhante violeta. A leitura foi feita em espectofotômetro a $595 \mathrm{~nm}$.

Para determinação das atividades de $\beta$-1,3-glucanase nos extratos utilizou-se a metodologia de Wirth e Wolf (1992), também com adequações, utilizando como substrato curdlan-remazol azul brilhante (Sigma Aldrich ${ }^{\circledR}$ - 4 mg.ml-1), com o uso de $200 \mu \mathrm{L}$ do sobrenadante, $600 \mu \mathrm{L}$ de tampão acetato e $200 \mu \mathrm{L}$ de CM-curdlan-RBB (4,0 mg mL-1). Posteriormente incubou-se durante 20 minutos a $40 \mathrm{oC}$, adicionando $200 \mu \mathrm{L}$ da solução de $\mathrm{HCl}$ 1,0 M para paralisação da reação. Em seguida, foi resfriado em gelo e centrifugado a $10.000 \mathrm{~g}$ por 5 minutos e realizada a leitura em espectofotômetro a $550 \mathrm{~nm}$.

Os resultados foram avaliados quanto à homogeneidade, e posteriormente submetidos análise de variância e quando significativos agrupados pelo teste de médias, devido aos tratamentos serem qualitativos e aos tempos serem distintos, ou seja, definidos, onde não se avalia ao longo do tempo e sim em tempos fixos, tornando-se qualitativos. O teste utilizado foi o Scott-knott a $5 \%$ de probabilidade de erro com uso do programa estatístico Assistat Versão 7.7 beta.

\section{RESULTADOS E DISCUSSÃO}

Em 24 horas os resultados já demonstraram interação significativa entre os fatores avaliados, havendo interferência na atividade da fenilalanina amônia-liase (FAL), sendo que o tratamento realizado com fosfito a base de cobre e manganês já demonstraram maiores níveis da enzima (Figura 1), diferindo da testemunha o fosfito de potássio e o ASM (menor nível de ativação enzimática). Com 48 horas ocorreu o pico de atividade de todos os produtos diferindo da testemunha o fosfito de cobre e manganês, Já com 96 e 192 horas, o único indutor que manteve níveis mais elevados da enzima foi o fosfito de cobre, estatisticamente diferente de todos os tratamentos. 


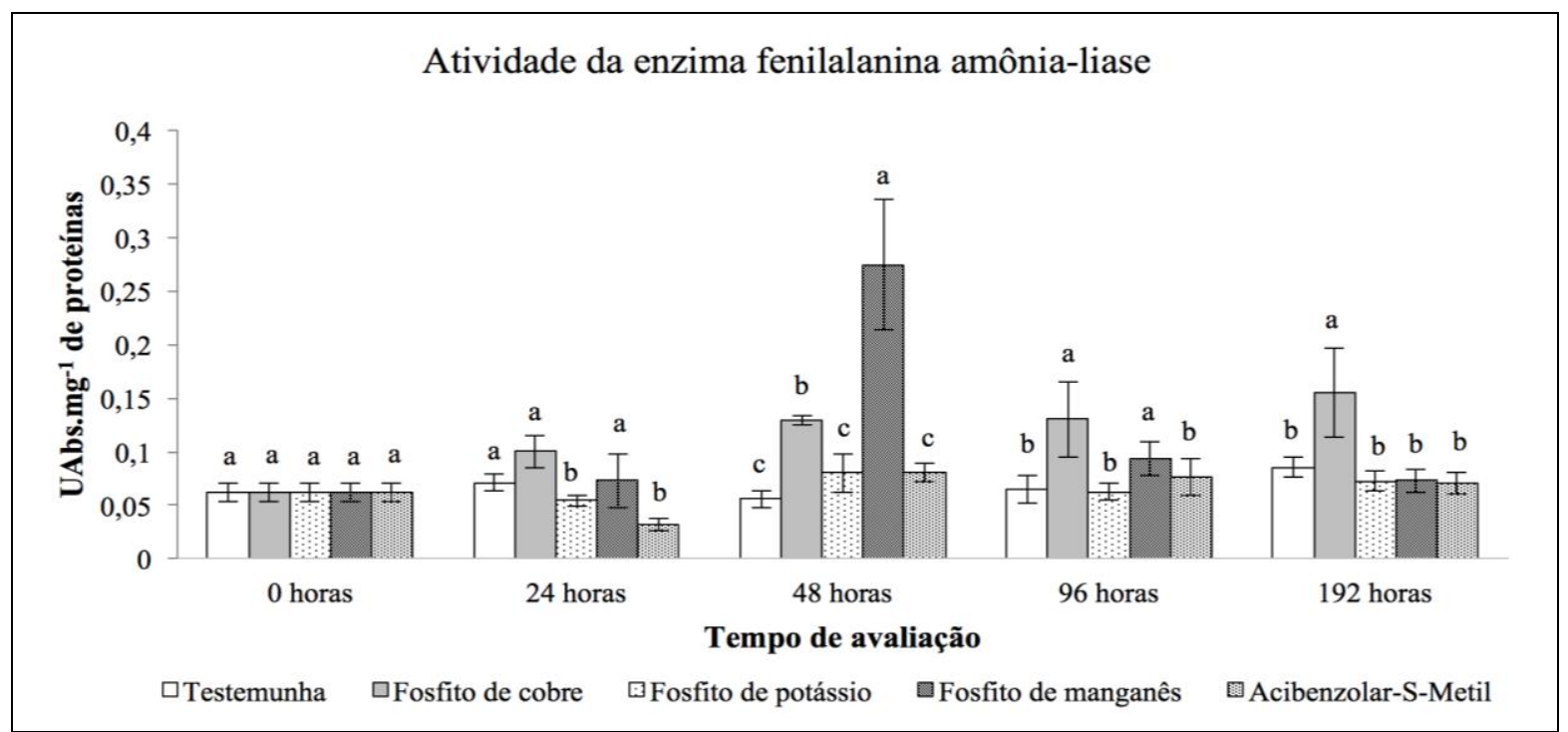

Barras na vertical indicam erro padrão. Letras minúsculas distintas diferem entre si nos tratamentos, letras maiúsculas distintas diferem entre si nos tempos de coleta, pelo teste de Scott-Knott a 5\% de probabilidade de erro. Dados foram transformados utilizando raiz quadrada $(\sqrt{ })$. $C V=19,2 \%$.

Figura 1. Atividade da enzima fenilalanina amônia-liase (FAL) em plantas de soja submetidas a aplicações de diferentes tratamentos e coletadas inicialmente e em intervalos de 24, 48, 96 e 192 horas após aplicação. UTFPR - Dois Vizinhos, 2016.

Tais resultados demonstram que os indutores possuem capacidade de ativar a rota de defesa vegetal dos fenilpropanóides para produção de compostos de defesa. Possivelmente, no caso do fosfito a base de cobre, ocorreu uma potencialização da ativação dessa rota, pois no produto comercial (Cubo®), além da presença de fosfito de cobre na composição, existem aminoácidos, que são cofatores, os quais podem ter ação na rota dos fenilpropanóides, ou até mesmo possam servir de substrato para a constituição de aminoácidos necessários para a ativação da rota.

Estudos conduzidos por LOCATELI (2017), demonstraram que o fosfito de potássio, bem como a quitosana, o silício, ASM e o ácido salicílico, na cultura da soja, possuem a capacidade de ativar mecanismos de defesa vegetal, pela ativação da enzima FAL como também a formação de compostos fenólicos. Assim como para MONTEIRO et.al (2014), onde verificou que o fosfito de manganês possui a capacidade de redução da intensidade da ferrugem no cafeeiro, pela indução da transcrição de genes de defesa, como a FAL e o $\beta-1,3$ glucanase.

A atividade da quitinase com 24 horas, o tratamento contendo ASM, ativou a enzima hidrolítica quitinase, mantendo-se elevado até 48 horas, foi nessa coleta onde todos os tratamentos apresentaram os maiores valores de atividade enzimática de quitinase (Figura 2). Para o fosfito de cobre, a maior atividade ocorreu com 48 horas mantendo-se ativo até 192 horas. Esses resultados demonstram que todos os produtos possuem o potencial de ativar a enzima hidrolitica quitinase, tal fato constata que as respostas ocorreram como processo de defesa ao patógeno inoculado, no caso a ferrugem rica em quitina em sua parede celular. 


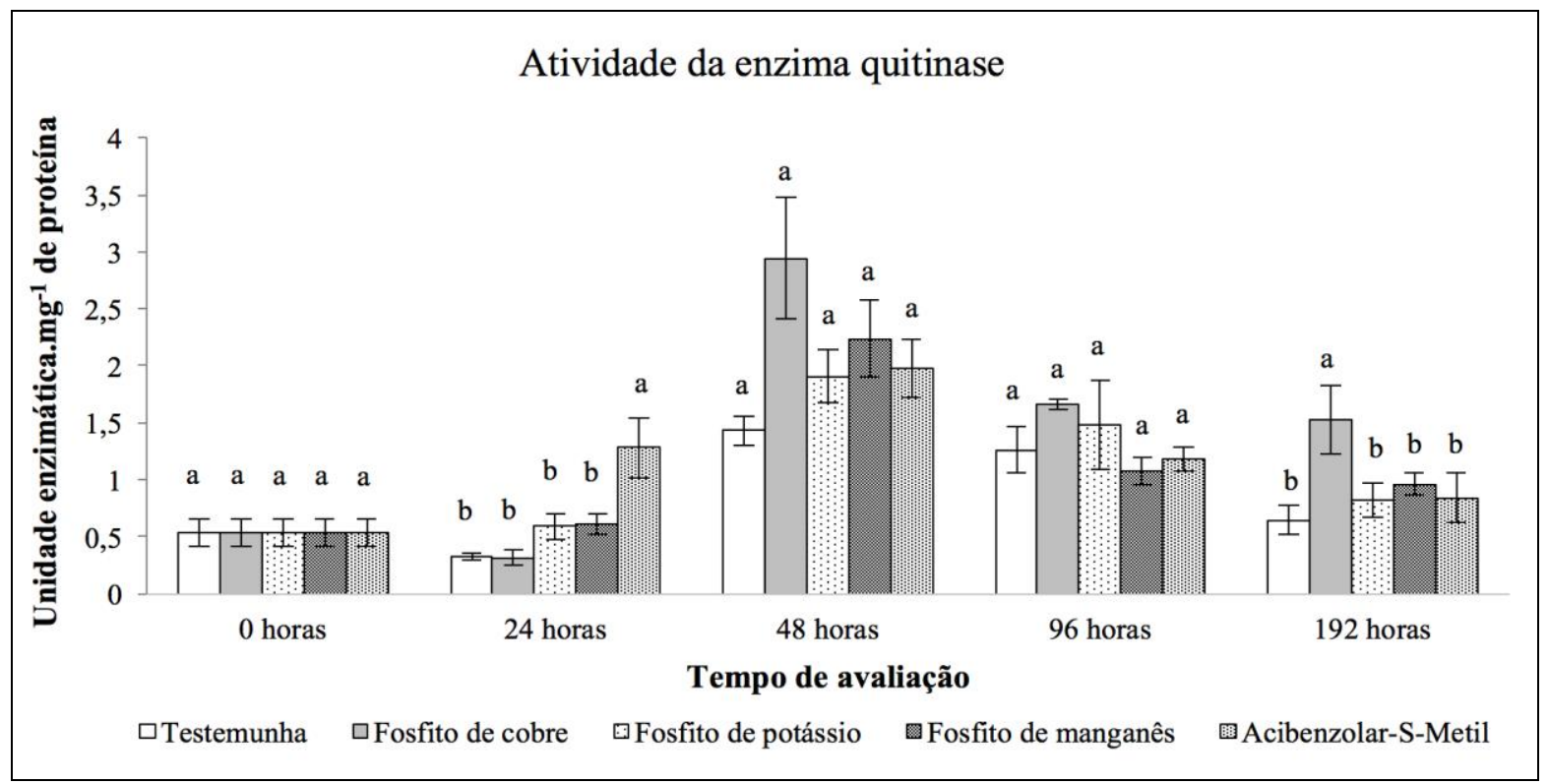

Barras na vertical indicam erro padrão. Letras minúsculas distintas diferem entre si nos tratamentos, letras maiúsculas distintas diferem entre si nos tempos de coleta, pelo teste de Scott-Knott a 5\% de probabilidade de erro. Dados foram transformados utilizando raiz quadrada $(\sqrt{ })$. $\mathrm{CV}=20,6 \%$.

Figura 2. Atividade da enzima quitinase em plantas de soja submetidas a aplicações de diferentes tratamentos e coletadas inicialmente e em intervalos de 24, 48, 96 e 192 horas após aplicação. UTFPR - Dois Vizinhos, 2016.

De acordo com COSTA et al. (2017), o uso de fosfito de potássio no controle de antracnose (Colletotrichum lindemuthianum) em feijão, aumentou a atividade de enzimas como a quitinase, $\beta-1,3$ glucanase, peroxidase e a superóxido dismutase, além de aumentar a quantidade de lignina e os níveis de fenólicos solúveis. Já para NASCIMENTO et al. (2016), a atividade da quitinase possui maior ativação pelo ASM, quando comparada ao fosfito de potássio e o silício, no controle da mancha marrom em arroz. Entretanto, para PEREIRA (2009), houve um aumento da atividade da quitinase com o uso de diferentes doses de fosfito de potássio, no controle do míldio na videira. Para ROMA (2013), houve redução da quitinase no uso de fosfito em diferentes concentrações, para o controle do micélio do patógeno (Rhizopus stolonifer) em bagas de uva, como hospedeira.

Para enzima $\beta-1,3$ glucanase, o fosfito a base de manganês demonstrou maior atividade com 48 horas, já para o ASM com 96 horas, e o fosfito a base de cobre com 192 horas (Figura 3). Esses resultados demonstram que todos os produtos apresentam capacidade de ativar a $\beta-1,3$ glucanase, sendo que o comportamento é distinto em relação ao tempo de indução, fato característico considerando as diferentes composições dos produtos. 


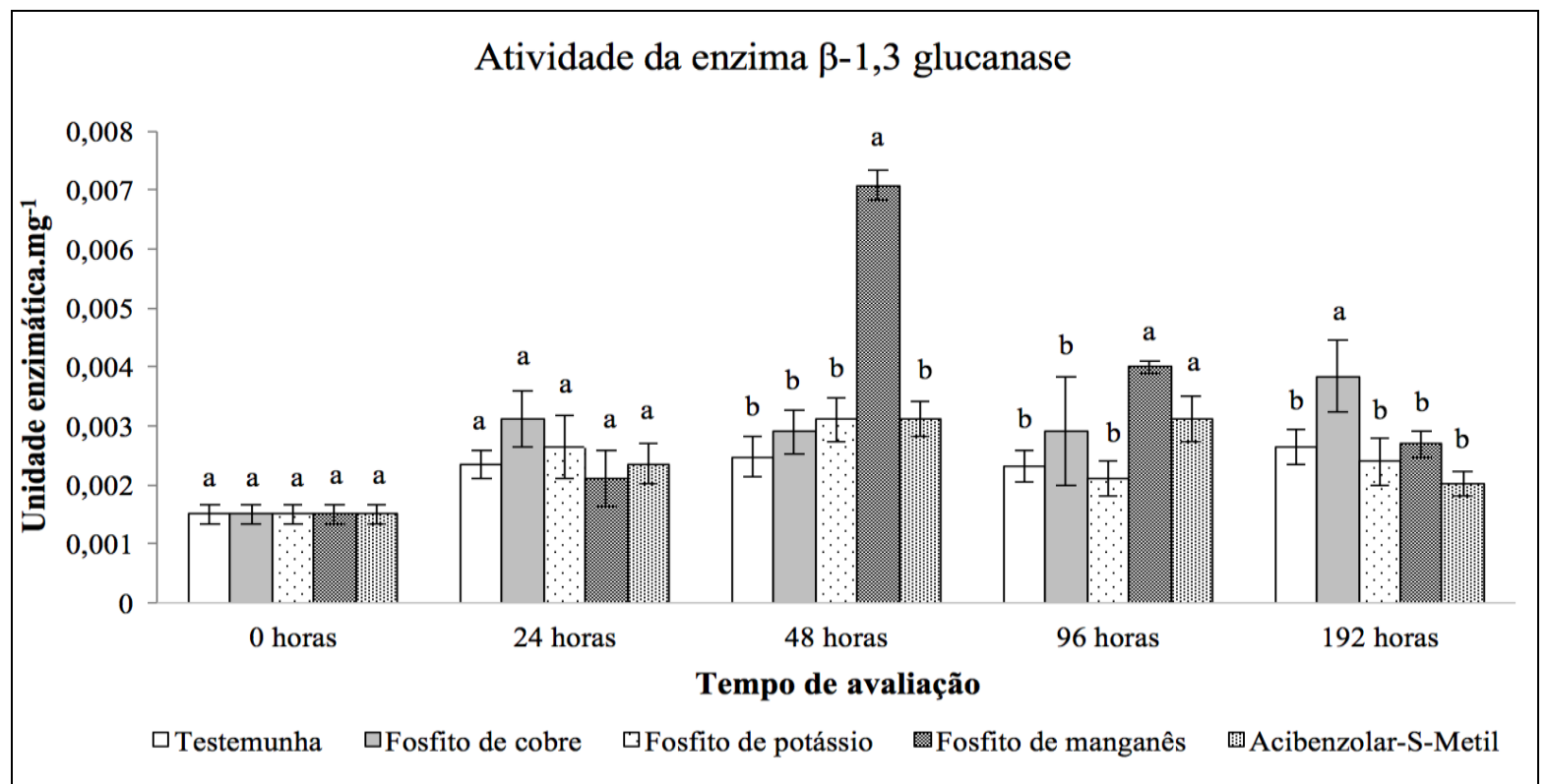

Barras na vertical indicam erro padrão. Letras minúsculas distintas diferem entre si nos tratamentos, letras maiúsculas distintas diferem entre si nos tempos de coleta, pelo teste de Scott- Knott a 5\% de probabilidade de erro. Dados foram transformados utilizando raiz quadrada $(\sqrt{ })$. $\mathrm{CV}=13,6 \%$.

Figura 3. Atividade da enzima $\beta-1,3$ glucanase em plantas de soja submetidas a aplicações de diferentes tratamentos e coletadas inicialmente e em intervalos de 24, 48, 96 e 192 horas após aplicação. UTFPR - Dois Vizinhos, 2016.

Importante também ressaltar que os produtos não priorizam somente uma rota de defesa, pois além de ocorrer a atividade da quitinase ocorreu a da $\beta-1,3$ glucanase, ambos mecanismos importantes na degradação da quitina e glucana presentes na parede celular do patógeno. Segundo RIBEIRO JÚNIOR (2008) a sua ativação em cafeeiro contra Hemileia vastatrix e Cercospora caffeicola, promoveu um aumento com a utilização de fosfito de potássio, manganês, assim como o ASM. No entanto, NASCIMENTO et al. (2016), a ativação da $\beta-1,3$ glucanase foi significativamente maior utilizando ASM, quando comparado ao fosfito de potássio e ao silício, no controle da mancha marrom (Bipolaris oryzae) em arroz. Já para MONTEIRO (2011), o fosfito de manganês induziu maior atividade da $\beta-1,3$ glucanase a partir da inoculação de Hemileia vastatrix, aos 8 e 9 DAP, havendo maior atividade antes da inoculação.

Em uma avaliação conjunta dos resultados, nos permite afirmar que os mecanismos de defesa estudados foram eficientemente ativados, seja a rota dos fenilpropanoides ou a ativação de enzimas hidroliticas.

Dessa forma, os resultados nos remetem para novos estudos, considerando o potencial desses produtos na ativação de mecanismos de defesa, se efetivamente constituem mecanismos de que permitam a redução da incidência ou severidade da doença.

\section{CONCLUSÃO}

De acordo com os resultados obtidos no trabalho apresentado, pode-se concluir que: 
1- Os fosfitos a base de potássio, cobre, manganês e o ASM, possuem capacidade de ativar enzimas relacionadas à patogenicidade, sendo que com isso demonstram a ativação da Resistência Sistêmica Adquirida em plantas de soja.

2- Tais ativações, demonstram que os fosfitos apresentam especificidade de ação, o que foi constatado em tempos distintos de ativação da defesa das plantas.

3- Também atuam em mecanismos distintos de defesa, seja a rota dos fenipropanoides pela ativação da FAL, ou de enzimas hidrolíticas, demonstrado pela ativação da quitinase e $\beta-1,3$ glucanase.

4- Os resultados são de suma importância, uma vez que o uso de fungicidas vem perdendo sua eficiência ao longo dos anos, tornando-se assim uma forma de controle alternativo no manejo da ferrugem asiática na soja.

\section{REFERÊNCIAS BIBLIOGRÁFICAS}

BRADFORD, M. M. A rapid and sensitive method for the quantification of microgram quantities of protein utilizing the principle of protein-dye binding. Analitical Biochemistry, Athens, v. 72, n. 1-2, p.248-254, 1976.

CARMONA, M.; SAUTUA, F. Os fosfitos no manejo de doenças nas culturas extensivas. Revista Plantio Direto, Passo Fundo, p. 19-22, 2011. Disponível em: $<$ https://wp.ufpel.edu.br/consagro/files/2012/02/Os-fosfitos-no-manejo-de-doenças-nasculturas-extensivas.pdf>. Acesso em: 10 mai. 2016.

CARVAlHO, B. O; OliveIRA, J. A.; CARVAlHO, E. R.; ANDRADE, V. de; FERREIRA, T. F.; REIS, L. V. Action of defense activator and foliar fungicide on the control of Asiatic rust and on yield and quality of soybean seeds. Journal of Seed Science, Londrina, v. 35, n. 2, p.198-206, 2013. Disponível em: <http://www.scielo.br/pdf/jss/v35n2/09.pdf>. Acesso em: 25 abr. 2016.

COMPANHIA NACIONAL DE ABASTECIMENTO - CONAB. Acompanhamento de Safra Brasileira de Grãos. Monitoramento Agrícola - Safra 2016/2017, Brasília, v. 4, n. 6, p.118-134, 2017.

COSTA, B. H. G.; RESENDE, M. L. V.; MONTEIRO, A. C. A.; JÚNIOR, P. M. R.; BOTELHO, D. M. S.; SILVA, B. M. Potassium phosphites in the protection of common bean plants against anthracnose and biochemical defence responses. Journal of phytopathology, Ithaca, v. 166, n. 2, p.95-102, 2017. Disponível em: <http://onlinelibrary.wiley.com/doi/10.1111/jph.12665/abstract>. Acesso em: 05 fev. 2018.

DEBONA, D.; FIGUEIRÓ, G. G.; CORTE, G. D.; NAVARINI, L.; DOMINGUES, L. da S.; BALARDIN, R. S. Efeito do tratamento de sementes com fungicidas e acibenzolar-Smethyl no controle da ferrugem asiática e crescimento de plântulas em cultivares de soja. Summa Phytopathologica, Botucatu, v. 35, n. 1, p.26-31, 2009. Disponível em: <http://www.scielo.br/pdf/sp/v35n1/v35n1a04.pdf>. Acesso em: 23 abr. 2016. 
DIAS, G. B.; RANGEL, T. B. A. Indução de resistência em plantas: o papel do óxido nítrico. Revista Capixaba de Ciência e Tecnologia, Natal, v. 1, n. 3, p.1-8, 2007.

DURRAN, W. E.; DONG, X. Systemic Acquired Resistance. Annual Review of Phytopathology, Palo Alto, v. 42, n. 1, p.185-209, 2004.

EMPRESA BRASILEIRA DE PESQUISA AGROPECUÁRIA - EMBRAPA. Eficiência de fungicidas para o controle da ferrugem-asiática da soja, Phakopsora pachyrhizi, na safra 2016/17: resultados sumarizados dos ensaios cooperativos. Londrina: Embrapa Soja, 2017. 10 p. (Circular Técnica, 129).

EMPRESA BRASILEIRA DE PESQUISA AGROPECUÁRIA - EMBRAPA. Sistema brasileiro de classificação de solos. 3.ed. Brasília: Embrapa Solos, 2013. 353 p.

EMPRESA BRASILEIRA DE PESQUISA AGROPECUÁRIA - EMBRAPA. Tecnologias de produção de soja - Região Central do Brasil 2014. Londrina: Embrapa Soja, 2013. 265 p. (Sistemas de Produção, 16).

KOTTEK, M. J.; GRIESER, J.; BECK, C.; RUDOLF, B.; RUBEL, F. World Map of the Köppen-Geiger climate classification updated. Meteorologische Zeitschrift, Berlin, v. 15, n. 3, p.259-263, 2006. Disponível em: <http://koeppen-geiger.vuwien.ac.at/pdf/Paper_2006.pdf>. Acesso em: 05 fev. 2018.

KUHN, O. J. Indução de resistência em feijoeiro (Phaseolus vulgaris) por acibenzolarS-metil e Bacillus cereus: Aspectos fisiológicos, bioquímicos e parâmetros de crescimento e produção. Tese (Doutorado em Agronomia - Fitopatologia) - Escola Superior de Agricultura "Luiz de Queiroz, Universidade de São Paulo, Piracicaba, 2007.

LABANCA, E. R. G. Purificação parcial de elicitores presentes em Saccharomyces cerevisiae: Atividade como indutores de resistência em pepino (Cucumis sativus) contra Colletotrichum lagenarium e da síntese de gliceolinas em soja (Glycine max). 2002. 118 f. Dissertação (Mestrado em Agronomia - Fitopatologia) - Escola Superior de Agricultura “Luiz de Queiroz", Universidade de São Paulo, Piracicaba, 2002.

LOCATELI, B. T. Indução de resistência por agentes abióticos em soja à moscabranca. 2017, 65 f. Dissertação (Mestrado em Agrossistemas) - Universidade Tecnológica Federal do Paraná, Dois Vizinhos, 2017.

MELO, T. A.; ARAÚJO, M. U. P.; SERRA, I. M. R. S.; PASCHOLATI, S. F. Produtos naturais disponíveis comercialmente induzem o acúmulo de fitoalexinas em cotilédones de soja e mesocótilos de sorgo. Summa Phytopathologica, Botucatu, v. 43, n. 3, p.205-211, 2017. Disponível em: <http://www.scielo.br/pdf/sp/v43n3/0100-5405-sp-43-3-0205.pdf>. Acesso em: 10 fev. 2018.

MONTEIRO, A. C. A. Associação de indutores de resistência para o manejo de ferrugem do cafeeiro e análise bioquímica da resposta de defesa induzida. $2011.86 \mathrm{f}$. Dissertação (Mestrado em Agronomia - Fitopatologia) - Universidade Federal de Lavras, Lavras, 2011. 
MONTEIRO, A. C. A. Indutores de resistência no manejo da ferrugem e cercosporiose do cafeeiro (Coffea arabica): Análises bioquímicas e moleculares. 2014. 132 f. Tese (Doutorado em Agronomia - Fitopatologia) - Universidade Federal de Lavras, Lavras, 2014.

NASCIMENTO, K. J. T.; ARAUJO, L.; RESENDE, R. S.; SCHURT, D. A.; SILVA, W. L. da; RODRIGUES, F. A. Silicon, acidobenzolar-S-methyl and potassium phosphite in the control of brown spot in rice. Bragantia, Campinas, v. 75, n. 2, p.212-221, 2016. Disponível em: <http://www.scielo.br/pdf/brag/v75n2/0006-8705-brag-1678-4499281.pdf>. Acesso em: 21 abr. 2016.

NEVES, J. S.; BLUM, L. E. B. Influência de fungicidas e fosfito de potássio no controle da ferrugem asiática e na produtividade da soja. Revista Caatinga, Mossoró, v. 27, n. 1, p.7582 , 2014.

Disponível

em:

<http://periodicos.ufersa.edu.br/revistas/index.php/sistema/article/view/2720/pdf_88>.

Acesso em: 30 mai. 2016.

PEREIRA, V. F. Fosfitos no manejo do míldio da videira: Eficácia e modo de ação. 2009. 69 f. Dissertação (Mestrado em Fitopatologia) - Universidade Federal de Lavras, Lavras, 2009.

RIBEIRO JÚNIOR, R. P. M. Fosfitos na proteção e na indução de resistência do cafeeiro contra Hemileia vastatrix e Cercospora coffeicola. 2008. 105 f. Tese (Doutorado em Agronomia) - Universidade Federal de Lavras, Lavras, 2008.

ROMA, R. C. C. Fosfito de potássio no controle de doenças pós-colheita em bagas de uva 'Itália' e possíveis mecanismos de ação à Rhizopus stolonifer. 2013. 117 f. Tese (Doutorado em Ciências - Fitopatologia) - Escola Superior de Agricultura "Luiz de Queiroz", Universidade de São Paulo, Piracicaba, 2013.

SCHMITZ, H. K.; MEDEIROS, C. A.; CRAIG, I. R.; STAMMLER, G. Sensitivity of Phakopsora pachyrhizi towards quinone-outside-inhibitors and demethylation-inhibitors, and corresponding resistance mechanisms. Pest Management Science, West Sussex, v. 70, n. $3, \quad$ p.378-388, 2013. Disponível em: <http://onlinelibrary.wiley.com/doi/10.1002/ps.3562/abstract; jsessionid=7C61B070237DD0 ACD58E8FD8F3B4A82D.f01t04?userIsAuthenticated=false\&deniedAccessCustomisedMe ssage $=>$. Acesso em: 12 abr. 2016.

WIRTH, S. J.; WOLF, G. A. Micro-plate colorimetric assay for endo-acting cellulase, xylanase, chitinase, 1,3- $\beta$-glucanase and amylase extracted from forest soil horizons. Soil Biology and Biochemistry, Mandan, v. 24, p.511-519, 1992.

XAVIER, S. A.; CANTERI, M. G.; BARROS, D. C. M.; GODOY, C. V. Sensitivity of Corynespora cassiicola from soybean to carbendazim and prothioconazole. Tropical Plant Pathology, Londrina, v. 38, n. 5, p.431-435, 2013. Disponível em: <http://www.scielo.br/pdf/tpp/v38n5/tpp_2013-0020.pdf>. Acesso em: 13 abr. 2016. 